\title{
Non-Religion and Atheism
}

\author{
Caleb Schaffner and Ryan T. Cragun
}

\section{1 \\ Introduction}

The other chapters in this part examine the process and experience of leaving a variety of different religions. However, there are several topics that those other chapters do not address, and the aim of this chapter is to fill some of these lacunae. Specifically, we are hoping to offer some insight into both the beliefs of those who have left religions in general - in our particular case, atheists and explore how confident atheists are that they have made the correct decision. In a sense, then, we are examining those who have already left religions, but with the aim of understanding how certain they are in their new beliefs. This connects back to the broader topic of leaving religion both because the people who were interviewed for this study all left religions but also because it is exploring whether those who have left religion in general consider returning to religion.

We explore two aspects of this question. First, we examine the various ways that atheists understand their new worldview, as not all atheists understand atheism to mean the same thing. Second, we explore how dogmatic atheists are with their new beliefs. Are atheists open to the possibility that they are wrong? And, if so, to what extent are they open to this possibility?

To address these questions, we draw upon data gleaned from 201 surveys and fifty semi-structured interviews with Chicagoland atheists who had exited religion. The former contained scales measuring childhood religiosity, childhood religious ethnocentrism, and present-day dogmatism, which form our quantitative analysis. Fifty interviewees were randomly selected from survey participants. Interviews lasted twenty to seventy minutes, investigating present-day beliefs concerning atheism, among other topics. Many reflected on their previous theistic beliefs, offering varying degrees of certainty that they would not return. Their explanations are the focus of our qualitative analysis.

\section{Previous Research and Empirical Material}

Religious beliefs (and disbeliefs) often are central to people's identities, serving as a foundation upon which more mundane beliefs rest. Thouless (1935) noted 
that respondents in his research rated their belief or disbelief in god as more certain than ordinary, knowable topics. Given the primacy many attach to religion (or atheism), there are advantages to being certain. Those most certain about the existence of god rate higher in emotional stability and life satisfaction, regardless of whether they are certain of god's existence or non-existence (Galen and Kloet 2011).

Interestingly, there is no consensus about the epistemological belief required to be a genuine atheist, even among researchers and authors. Some atheist literature (for example Cliteur 2009) uses a lenient definition, describing it merely as the lack of belief in a deity. Often this is termed "negative atheism." One of the most prominent contemporary atheists, Richard Dawkins (2006), would fall into this camp, describing himself as just shy of absolute certainty.

In contrast, many dictionaries (for example Merriam Webster and Cambridge) use a stricter, positive atheist definition, that is the complete certainty that a god does not exist. In her publications, Madalyn Murray O'Hair would often define atheism in this way, stressing an atheist must completely reject the possibility of any deity (Schaffner 2012). Around the world, the number of people who identify as positive atheists is increasing, but projections based primarily on fertility rates suggest that atheists may shrink as a percentage of the world's population in coming decades due to higher rates of fertility in predominantly religious countries (Pew Research Center 2015). However, within developed countries, the percentage of people who are atheists and/or nonreligious is increasing and projected to continue to increase (see also Stinespring and Cragun 2015). Below, we explore how the individuals we interviewed understand atheism and illustrate that their conceptions of atheism are varied and nuanced.

In addition to trying to understand how those who have left religions understand their new beliefs, prior research has also begun to explore the extent to which individuals who have left religions are confident they have made what they perceive to be the correct decision. In other words, how dogmatic are atheists? One possible contributor to the dogmatism of atheists that prior research has noted (Hunsberger and Altemeyer 2006) but not adequately tested is whether the religion in which atheists were raised was also dogmatic. If individuals raised in very dogmatic, ethnocentric religions who leave those religions remain dogmatic, this could be evidence for a hangover effect from one's prior religion. Variation in dogmatism is a prime domain to probe for evidence of residual or hangover influences from one's religious upbringing.

Some research has explored these types of hangover effects, like one's adherence to gender ideology (Cottee 2015) or dietary customs (Davidman 2014). However, one prominent hole in the exit literature concerns the effects of the 
religious intensity of one's upbringing on current dogmatism. It is possible that the strength of one's religious upbringing may resonate into the present day.

Hunsberger and Altemeyer (2006) suggest that a deeper and more intense experience with theism may increase the certainty that it is incompatible with oneself, resulting in increased atheist dogmatism. Altemeyer (2012) maintained this hypothesis in a personal correspondence, predicting a weak-to-moderate positive correlation $(r=+.3)$ between religious emphasis during one's upbringing and present-day dogmatism. We test this hypothesis below.

Although very little prior research supports it, the inverse is also possible: higher levels of religiosity during one's upbringing may result in lower levels of atheist dogmatism. Having been a devout believer growing up only to leave the faith may allow one to view their current beliefs more tentatively, as the best available explanation rather than as a certainty. Below we present some data that allow us to examine whether childhood religiosity influences the dogmatism of atheists.

\section{3}

\section{New Findings Focusing on "leaving religion"}

After leaving their original religion, our interviewees took a variety of trajectories which all eventually culminated in atheism. Roughly twenty-eight percent considered themselves atheists immediately upon leaving their original religion. Another nine percent formally joined another religion before they ceased believing in a god or higher power.

As noted, there is controversy in defining atheism. Responses from our interviewees revealed similar variability, with some stressing certainty that a deity does not exist and others offering less certainty. Survey participants identified themselves as having one of four epistemological stances about the existence of a deity: positive atheists, hard agnostics, soft agnostics, and apathetic atheists. Positive atheists are completely certain of the non-existence of any deity. These were the single most numerous epistemological group, comprising forty-four percent of all valid survey responses. Representing the dictionarydefinition of atheist, their explanations were numerous, but generally terse. In comparison, those who were not positive atheists devoted considerable interview time to explaining their stances and justifying their application of the "atheist" label, apparently aware that their claims would be contested by some of their peers.

Unlike most positive atheists, Regina ${ }^{1}$ offered her reasoning at length. It proved memorable and unique among the fifty interviews. She reasoned that,

1 All names are pseudonyms. 
as the non-existence of anything is unprovable, atheism entails a degree of faith, whereas agnosticism does not. She defined atheism as a religion, whereas agnosticism is a stance about how knowable god or gods are. Implicit here is that religion is defined by faith in something that cannot be conclusively proven:

I think atheism is a religion. I believe being agnostic is non-religious. But I think atheists... You have to believe that there is no god. Agnostic you don't really know. You need proof in either direction. There is no proof that god does not exist. There's just a lack of evidence that he does. You really have to believe that he doesn't exist. So I count that as religion.

Most interesting about Regina's delineation was its resemblance to tactics used by the Religious Right to oppose and attempt to diminish the teaching of evolution and secular morality in classrooms, by equating them with religious faith. Regina was cognisant that this stance differed from the majority of rankand-file atheists, pointing to it as the key way she differed from her peers:

And the way that I definitely know I differ from other atheists is the fact that I do think of atheism as a religion. I don't think a lot of atheists think that we have to have faith to be atheists. But I definitely think that you have to have faith to be atheists: faith in the lack of god, as opposed to faith in a god.

Again, Regina was distinct as far as the interview sample was concerned. While others were similarly certain, most stress the impossibility of a deity, rather than explicitly portraying atheism as tantamount to religion. She was the only one to wrestle with how to prove a negative and attempt to resolve it in such a manner.

Those who were epistemologically hard agnostics stated that they did not think it was possible for humans to ever definitively know whether or not god exists. Like Regina, Trent similarly talked about the impossibility of proving a negative like the non-existence of a deity. While Regina solved this impasse by stressing that atheism is a faith (and that she was among its faithful), Trent took a different route. As it is impossible to prove the existence of a negative, all atheists are necessarily agnostic by definition, according to Trent.

Trent: Well, I mean, basically I think to an extent every atheist is agnostic. Because you just can't know if there's a god. I mean it's infallible. Interviewer: Would you want to elaborate a bit, on how it's truly unknowable in the end? 
Trent: Yeah. The claim that if I said I have an invisible dinosaur in my backyard. You can't see him or feel him. Only I can. If no one's looking. That's an infallible statement. No one can say that surely doesn't exist. That's basically god. Because we don't really know his attributes. People have different points of view of what god is. The Christian god on the other hand, you can basically say he's untrue, because of different historical events that never happened the flood and stuff like that, that are attributed to him.

While Trent and Regina both used broad brush strokes to address the lines between atheism and agnosticism, they painted different pictures. Trent framed atheists as a subgroup within the broader category of agnostics, while Regina designated atheism a religious category, distinct from the areligious, epistemological category of "agnostic."

The final three sentences in Trent's reply illuminate how atheists can exhibit certainty that their beliefs will not change. Trent - and other atheists - can be certain about the non-existence of the gods of world religions because those deities have miracles and historical events attached to their names, which can be falsified by scientific investigation or the lack of corroborating evidence. In contrast, when Trent talked about being unable to definitively prove the nonexistence of a god, he was talking about a deity in the abstract sense: a Deist conception of god, which has no specific worldly effects to investigate.

Those whose beliefs made them soft agnostics limited the above statement to themselves, stating that they personally did not know whether or not a deity exists. After leaving religion, Lionel initially considered himself to be agnostic, before self-identifying as atheist. When pressed for any additional argument or event which precipitated this shift, Lionel could not point to any precise watershed moment. Instead, he stated:

At that point it was maybe a switch in the label I would use. But it wasn't that I had a huge switch in my belief then... Technically I wouldn't even quite call myself an atheist today, just because I don't put too much stock in my ability to be sure in such a fundamental thing. I just think they're plenty of things with the universe that I'm not capable of understanding. And its ultimate cause in nature is probably the biggest. But, that said, I think that the possibility of there being a god is so extremely unlikely that for all intents and purposes I'm an atheist.

Lionel's reasoning was not unique among the interviews. Several other participants mentioned being personally unsure to some degree. Multiple 
respondents actually quantified their certainty of a god's non-existence: 99-point-some-amount-of-nines-repeating percent. Lionel and these other respondents essentially "rounded up" to consider themselves atheists. Lionel's stance was distinguished from Trent's by the scope of uncertainty: whereas Trent did not consider it possible for humans to ever be certain of the nonexistence of god, Lionel's response was more measured, limited to himself

Finally, the epistemologically apathetic were unconcerned with whether or not a deity exists. Patrice started from a point similar to Trent, laying the foundation for explaining his lack of complete certainty with a metaphor. However, he fell into a different category than Trent: epistemologically apathetic.

Patrice: And even though I don't believe in god, I don't believe god exists, I don't know there's no higher power, obviously. I don't believe one exists and I don't believe if it did exist - hypothetically speaking - I don't believe it would care anything about what's going on here. But I can't know for sure. And I know that theoretically that's supposed to be agnostic. But I don't believe in the god in the same way that I don't believe that the moon is made of cheese. I don't believe in it but it's not like an ambiguous 'I don't believe in it,' I don't believe in it because there's no reason to. So I identify as atheist even though the more atheist purists would call me 'agnostic.'

Interviewer: Functionally atheist as opposed to epistemologically atheist? Patrice: Yeah. That's a good way to put it. Functionally atheist, that's a good way to put it.

Where Patrice diverged from Trent is how he handled this inability to prove a negative. Trent concluded that it is beyond the realm of human ability to do so. In contrast, Patrice did not care about the proposition, opting to live his life as a functional atheist and put the prospect out of his mind.

Furthermore, Patrice's assertion that "there's no reason to" believe in a god that would not "care about what's going on here" demonstrated that, similar to Trent, he conceptualised such a deity as wholly removed and uninterested in human affairs. Often, negative atheists do not rule out what they conceptualise as a deistic god, while they feel completely confident stating that more specific conceptions of a god - such as the Abrahamic god - do not exist.

The "functionalist atheist" label accurately summarised Patrice's decision to live his life without concern about a god or religious dogma. Others used similar terminology, such as Glenn, who stated, "I guess I live my life as a de facto atheist. I don't live my life in a way that I believe there's going to be any kind of retribution by a deity." Underscoring that one's actions are identical to positive 
atheists is one key avenue which negative atheists use to legitimise their application of the "atheist" label.

We now turn to our findings regarding dogmatism. In recounting their exit narratives, sixty percent of interviewees researched joining another religion, though very few formally joined any. The religions researched ranged from Islam to Bahá'í to Mormonism. Seven interviewees had a brief quest phase, researching and entertaining the possibility of joining multiple different religions. Some immediately dove into atheism, while others first dipped their toes into multiple religions. Eventually, all respondents reached a level of certainty that no religion is satisfactory and no argument could persuade them of the existence of any deity. In recounting acquaintances' futile attempts to persuade her to attend their church, Tracy memorably summarised their attitudes towards her disbelief:

I had somewhat similar experiences with other people, where they just think that if I just pray with them they'll change my mind. I'm afraid of dogs and people are like 'If you just meet my dog you'll be okay.' It's just the same thing with god.

Like Tracy, individuals must be confident enough in their disbelief to discount the possibility of ever amending some of their most central convictions in order to return to theism. However, in the interviews, there were differing levels of certainty. While many were positive that their beliefs could now never be changed by any life event or argument for theism, others' expectations were more tempered. Five interviewees specifically mentioned the potential reversibility of their beliefs. One clear example was Brad, who stated that "atheism is just a working assumption for my worldview."

Another case was Kelsey. She was a self-starter, raised by Catholic parents who were not particularly religious. At ten, she became more interested in religion, stressing, "I don't think that a change was noticeable to most people. It was very private." She prayed and read the bible frequently in her room. She also attended some Catholic retreats. Since leaving religion and becoming an atheist, she reported some concern that she may return to theism later in her life:

Kelsey: There's definitely a little bit of feeling that, since I was raised religious, a fear that maybe I would go back to it. And I really don't want to. And I think that's part of spending... I spent the first fifteen years of my life believing in something. And it's weird to think that for those 
first fifteen years I was wrong. And I'm afraid that someday when I'm old I will go back to it and I really don't want to. I guess that's a fear that I have...

Interviewer: That it's so ingrained in you that down the road you might want to?

Kelsey: Yeah. And definitely me right now I really hope not. But... yeah, it's definitely weird because it is taught at such a young age.

Brad and Kelsey demonstrate that some atheists consider it possible that their identity might not be permanent; their identity is capable of changing with more information or later in their lives. This possibility was unwelcome and greeted with concern, as in Kelsey's case where she really hoped she would not return to believing in a god or higher power. Nevertheless, the interviewees who mentioned the prospect served as one pole on the spectrum of dogmatism: a more cautious stance, contrasted with absolute certainty.

In light of Altemeyer's (2012) suggestion of a potential correlation between childhood religiosity and atheistic dogmatism, we specifically tested that claim using three scale measures. The first scale was a forty-point dogmatism measure that does not specifically reference religion. The mean in our sample was 17.0; the standard deviation was 5.8. We also developed two measures of childhood religiosity. The first measured emphasis placed on religiosity in one's childhood. This scale ranged from zero to forty-eight, with a mean of 25.1 and standard deviation of 13.0. The second measured how ethnocentric or exclusive one's childhood religion was. This scale ranged from zero to twenty-four, with a mean of 11.6 and standard deviation of 6.7. We regressed these variables along with a variety of control variables on dogmatism (results not shown), but for parsimony we report here simple bivariate correlation coefficients.

TABLE 20.1 Correlations Between Dogmatism, Religiosity, and Religious Ethnocentrism $\left({ }^{*} \mathrm{p}<.05,{ }^{* *} \mathrm{p}<.01\right)$

\begin{tabular}{|c|c|c|c|}
\hline & Dogmatism & Religiosity & $\begin{array}{l}\text { Religious } \\
\text { Ethnocentrism }\end{array}$ \\
\hline \multicolumn{4}{|l|}{ Dogmatism } \\
\hline Religiosity & .01 & & \\
\hline Religious Ethnocentrism & $.17^{*}$ & $.71 * *$ & \\
\hline
\end{tabular}


Only childhood religious ethnocentrism behaves according to Altemeyer's (2012) predictions, exhibiting a positive correlation with dogmatism which is significant at a .05 level. Childhood religiosity has no discernable impact on dogmatism. In fact, upon controlling for its considerable overlap with childhood religious ethnocentrism, it actually has a marginal $(\mathrm{p}<.10)$, negative impact on dogmatism (results not shown).

Overall, the effects of one's childhood religion are nuanced, with the two prongs having unique effects. Childhood religious ethnocentrism behaves as hypothesised by Altemeyer's correspondence (2012). Recall his prediction was aimed at the umbrella concept of childhood "religious emphasis," rather than specifically on either prong which comprises it. Those raised with more negative views of other religious groups maintain the strict dichotomy between their own beliefs and others, even after overhauling their belief system upon exit. They remain steadfast in their new beliefs, seeing little chance of amending them in the future. This provides evidence that stances learned in religion can result in a hangover effect, with a continuation of the sharp differentiation between one's new, atheistic beliefs and competing options.

In contrast, childhood religiosity behaves opposite to initial expectations. While it has no effect when the only measure considered, controlling for childhood religious ethnocentrism isolates its unique contributions. When comparing two individuals who received identical messages concerning their faith's acceptance of outside groups, the individual with a more religious upbringing is expected to be less dogmatic in the present day. Being so personally invested in a religion, only to eventually exit can sensitise one to the tentative nature of their present beliefs.

Kelsey serves as a perfect example, as seen in her survey results. She ranked above average in childhood religiosity, yet below average in childhood religious ethnocentrism. Believing so fervently in her pre-teens and early teens, only to eventually leave, made it conceivable that her beliefs may again change. The tendency to belief might be deeply ingrained inside her. Her explanation contains two strands: cognisance that even one's most central beliefs can drastically change and the possibility that a tendency towards Catholicism cannot ever be completely uprooted.

For those whom religion was a particularly central aspect of their identity growing up, their childhood dogmatism may persist even in light of shifts in other beliefs and values. Specific, consciously-recognised instances of residual influences of one's childhood religion appear to survive the transition to atheism. Our data suggest that being raised with a strong distinction between one's in-group and out-group carries over to new beliefs to some degree, even 
as one switches religious reference groups. Some maintain a strict distinction between their beliefs and others, stressing certainty in the superiority and ultimate correctness of their present answers to major, existential questions. But the correlation is not particularly strong, suggesting that this is true of just a minority of atheists or a generally weak effect. For other atheists, having been deeply invested in a belief system only to exit leads one to consider the tentative nature of their present beliefs. Further analysis is needed, but our results suggest a small, persistent effect of one's childhood religion, even when the specific faith - and theism in general - is disavowed.

Our aim in this chapter has been to illustrate that among those who have left religion in general, in our case atheists, there is not universal certainty. What it means to be an atheist differs, with some insisting on the non-existence of any and all gods, while others find the question irrelevant to their daily lives. Likewise, the degree of confidence atheists exhibit in their new worldview varies and appears to have at least some connection to childhood religiosity, even if the relationship is not particularly strong. As the other chapters in this part illustrate, many people leave religions. While most atheists and a growing percentage of the nonreligious are remaining atheists and nonreligious, respectively (see Merino 2011), our research suggests that there is the possibility that members of both groups could change their views and adopt theism or join a religion. However, such transitions are uncommon. As secularisation theorists have long argued (Bruce 2013), once you go secular, you rarely go back.

Our chapter illustrates that scholars are just beginning to explore the process of leaving religion in general. In order to have a clear understanding of what it is like to become nonreligious, scholars need better ways of measuring types of nonreligion, like those we employed above, as well as better ways of measuring types of religious upbringing. In addition to these variables, it is, of course, necessary to understand the environment in which a religious exit takes place (for example, How religious is the surrounding society? Family? Friends?) and an individual's social location (for example, Are they part of a racial and/or gender majority? Are they well-educated? Wealthy?). Tentatively, we suggest that, while childhood religious experience will no doubt be filtered through variables like environment and social location, it may remain an important factor influencing how nonreligion and atheism are manifest after people leave religions. 


\section{References}

Altemeyer, B. 2012. Email correspondence. 3/4/2012.

Bruce, S. 2013. Secularization: In Defence of an Unfashionable Theory. Oxford: Oxford University Press.

Cliteur, P. 2009. "The Definition of Atheism." Journal of Religion and Society. 11, 1-23.

Cottee, S. 2015. The Apostates: When Muslims Leave Islam. London: C. Hurst and Co.

Davidman, L. 2014. Becoming Un-Orthodox: Stories of Ex-HasidicJews. New York: Oxford University Press.

Dawkins, R. 2006. The God Delusion. Boston: Houghton Mifflin.

Galen, L.W., and Kloet, J.D. 2011. "Mental Well-Being in the Religious and the NonReligious: Evidence for a Curvilinear Relationship." Mental Health, Religion, and Culture. 14: 7, 673-689.

Hunsberger, B.E., and Altemeyer, B. 2006. Atheists: A Groundbreaking Study of America's Nonbelievers. Amherst, NY: Prometheus Books.

Merino, S.M. 2011. "Irreligious Socialization? The Adult Religious Preferences of Individuals Raised with No Religion." Secularism and Nonreligion. 1:0, 1-16.

Pew Research Center. 2015. The Future of World Religions: Population Growth Projections, 2010-2050. At http://www.pewforum.org/files/2015/03/PF_15.04.02_Projec tionsFullReport.pdf. Accessed 14/5/2015.

Schaffner, C. 2012. "Filling in the Definition of 'Nones': Framing in the Early Atheist Movement." Delivered, Midwest Sociological Society Conference. Minneapolis, 29/3/2012.

Stinespring, J., and Cragun, R.T. 2015. "Simple Markov Model for Estimating the Growth of Nonreligion in the United States." Science, Religion, and Culture. 2: 3, 96-103.

Thouless, R.H. 1935. "The Tendency to Certainty in Religious Belief." British Journal of Psychology. 26: 1, 16-31. 